\title{
Use of psychiatric drug treatment services by heroin users from general practice
}

\author{
AIDAN B V BUCKNALL, J ROY ROBERTSON, JAMES G STRACHAN
}

\begin{abstract}
Centres for the treatment of drug abusers are often integrated with regional psychiatric hospitals and are the focus of the British response to opiate addiction. Little is known, however, about the use made of these services by drug users in the community or about the success of these services. This study examined the use made of one centre offering a detoxification service by a cohort of 183 heroin users from a large Scottish general practice. Over half of this cohort were referred to the psychiatric drug treatment service, but less than one third started treatment. The evidence did not indicate that patients who had extended contact with the psychiatric service showed prolonged abstinence, though methodological difficulties necessitate further prospective studies.
\end{abstract}

This study raises important questions about the value and appropriateness of this type of service in the light of the pattern of voluntary remission and relapse displayed by heroin users and in the absence of adequate provision for drug abusers in the community.

\section{Introduction}

In 1965 the second Brain committee recommended that hospital based treatment should be the priority in tackling the emerging

Edinburgh Drug Addiction Study, West Granton Medical Group, 1 Muirhouse Avenue, Edinburgh EH4 4PL

AIDAN B V BUCKNALL, BSC, research associate

J ROY ROBERTSON, MB, MRCGP, general practitioner

Andrew Duncan Clinic, Royal Edinburgh Hospital, Edinburgh EH10 5HF JAMES G STRACHAN, MPHIL, MRCPSYCH, consultant psychiatrist

Correspondence to: Dr Robertson. problem of drug abuse. ${ }^{1}$ Throughout the United Kingdom there are now 106 centres with this function, usually major regional psychiatric hospitals. ${ }^{2}$ Few of these, however, have specialised units exclusively for the treatment of drug dependence, and the centre in Edinburgh, like most others, treats drug dependence as part of a general psychiatric service. Drug abusers, like other psychiatric patients, attend the general outpatient clinics and, when necessary, are offered admission to general inpatient wards alongside patients with a variety of psychiatric diagnoses.

In recent years attitudes towards the management of drug abusers have changed considerably, largely in response to progressive disillusionment with maintenance treatments. ${ }^{34}$ The 1982 report of the Advisory Council on the Misuse of Drugs identified the need for a more broadly based system featuring hospital based detoxification combined with outpatient support from psychiatric and primary health teams, social workers, and non-statutory agencies. ${ }^{5}$ As the scale of drug abuse in Britain escalates beyond the levels foreseen at the inception of these centres, however, there is little multidisciplinary coordination and scant information on the uptake, activity, and efficacy of existing psychiatric drug treatment services. ${ }^{6}$

Studies of drug dependence clinics have often failed to produce the information critical for planning policies for treatment. Love and Gossop, in attempting to describe what was actually being done in the clinics, investigated the process of referral and the progress of patients through a specialised London unit, "one of a few such facilities in the UK," which was not, therefore, representative of most unspecialised psychiatric drug treatment services available. ${ }^{7} \mathrm{~A}$ particular problem in previous studies was that no information was available on patients who had never been referred to the unit, and no follow up of these or the referred patients attempted to evaluate the effect of referral and treatment itself.

Within the limits of available data the present study confronted some of these issues by examining the uptake of an unspecialised Scottish psychiatric drug treatment service by a cohort of heroin users attending a single general practice, and looking at the 
outcome. Collaboration between the psychiatric and general practice services and the use of general practice records, a resource rarely used in such studies, meant that both patients who were referred and those who were not referred could be followed up.

\section{Patients and methods}

Recent studies identified and described a cohort of patients from a large general practice, all known to be, or to have been, using heroin. ${ }^{8}$ Psychiatric services for the practice were provided by the Royal Edinburgh Hospital, the

TABLE I-Sources of referrals to psychiatric services and proportion leading to treatment

\begin{tabular}{lrr}
\hline \multicolumn{1}{c}{ Source } & $\begin{array}{c}\text { No(\%) of } \\
\text { referrals }\end{array}$ & $\begin{array}{c}\text { No (\%) leading } \\
\text { to treatment }\end{array}$ \\
\hline General practice & $137(55)$ & $50(36)$ \\
Self referral & $49(20)$ & $30(61)$ \\
Legal (eg, court and prison reports) & $28(11)$ & $5(18)$ \\
General hospital or accident and emergency department & $17(7)$ & $9(53)$ \\
Regional poisons unit & $13(5)$ & $3(23)$ \\
Social work department & 7 & $3(43)$ \\
\hline Total & $251(100)$ & 100 \\
\hline
\end{tabular}

designated drug treatment centre for the Lothian region. The regional catchment of the hospital ensured that even if patients moved away from the practice but stayed within the city of Edinburgh, or were referred by agencies other than the general practitioner, their case notes were still centralised and available for study. A search of the records at the hospital showed the contacts made with a cohort of 183 heroin users up to July 1985 . All notes for those referred were retrieved and standardised case summaries made. Similarly, general practice records were searched and summarised, particular attention being paid to those of patients still using heroin. Most heroin users from this cohort attended the practice regularly (often as many as two or three times a week over many months) and were well known to the doctors, which permitted a degree of follow up that would not otherwise have been possible.

\section{Results}

\section{UPTAKE OF SERVICE}

Of the 183 heroin users known to the general practice, 110 were found to have had some contact with the psychiatric services. Of these, 96 had been referred specifically for their misuse of drugs and the remainder for other psychiatric disorders. Figure 1 shows their progress. Of 81 patients attending an appointment for a first assessment, 60 returned for further contact with the psychiatric service and were therefore considered to have begun treatment. No sex bias was observed between the five different

TABLE II-Patients abstaining from and patients still using heroin at last medical contact (figures are numbers (\%) of patients)

\begin{tabular}{lccrrr}
\hline & $\begin{array}{c}\text { Patients not referred or } \\
\text { referred but not because of drugs }\end{array}$ & $\begin{array}{c}\text { Referred patients never seen by } \\
\text { psychiatric services or not treated }\end{array}$ & $\begin{array}{c}\text { Patients who started } \\
\text { treatment }\end{array}$ & Total \\
\hline Still using heroin & $55(63)$ & $18(50)$ & $43(72)$ & $116(63)$ \\
Abstinent & $15(17)$ & $6(17)$ & 4 & $(7)$ & $25(14)$ \\
Insufficient data & $17(20)$ & $12(33)$ & $13(22)$ & $42(23)$ \\
\hline Total & $87(100)$ & $36(100)$ & $60(100)$ & $183(100)$ \\
\hline
\end{tabular}

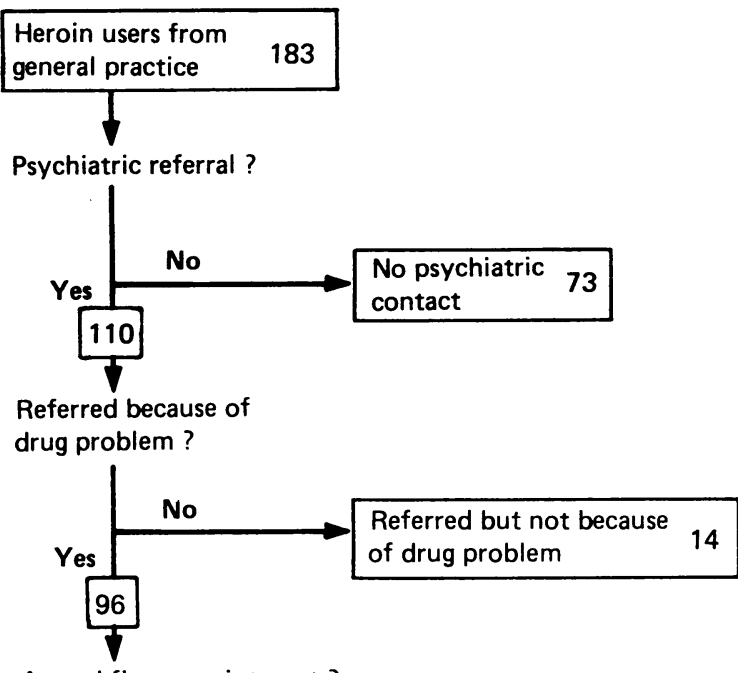

Attend first appointment ?

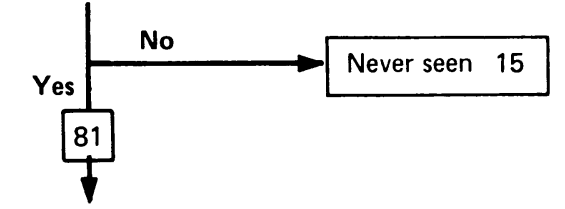

Extended psychiatric contact?

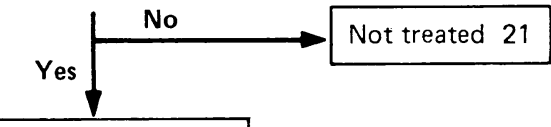

Start treatment 60

FIG 1-Flow chart showing progress of heroin users from general practice to psychiatric service. categories of outcome shown in figure 1 , though the overall sex ratio was found to be $2 \cdot 16$ men to one woman. There was, however, a significant difference in the mean age of patients referred for problems of heroin dependence $(27 \cdot 7$ years $)$ and those not referred $(23.9$ years $)(t=4.89,181 \mathrm{df}$, $p<0.05)$. Patients were almost exclusively from social classes IV and V, the general practice being in a large deprived area of the city.

\section{REFERRAL}

Altogether 251 referrals for drug dependence were made to the psychiatric drug treatment service (average $2 \cdot 61$ /patient referred, range $1-11$ ). Table I shows the sources of the referrals and the proportion of patients who received treatment. The time between referral and the first appointment offered by the drug treatment service was assessed; 120 first appointments were offered within one week after referral, 49 of these being self referrals, whereby patients presented directly to the emergency psychiatric service. Fifty one patients were offered an appointment within one to four weeks after referral and 25 after one month. Waiting times could not be determined for 55 patients. The response to a request for help was, therefore, generally rapid. There was a significant correlation between the length of time between referral and the first appointment and attendance at the first appointment $\left(\chi^{2}=11.04,2 \mathrm{df}, \mathrm{p}<0.01\right)$. The first appointment was not attended in $70(28 \%)$ cases overall, with a similarly high rate of nonattendance at further follow up ( 45 cases, $18 \%$ ). In 30 cases (usually patients referred because of court reports) no follow up was proposed after the first contact, and in six cases the outcome of the first contact could not be established. Thus only 100 referrals (of 60 patients) resulted in extended contact with the psychiatric service.

Figure 2 shows the rapid increase in the number of referrals to the service in the past 20 years, though some dropping off was apparent in 1984 and only eight referrals were made in the first half of 1985

\section{TREATMENT AND OLTCOME}

Sixty patients agreed to continue contact with the psychiatric service after 100 referrals. On 67 oceasions this entailed inpatient detoxification and on 33 
occasions outpatient contact (because of hepatitis B positivity). When possible social workers attached to the psychiatric service visited the patient and his family at home to discuss expectations and plans for the period after detoxification. Those receiving inpatient detoxification were admitted to a general psychiatric ward for a proposed minimum of two weeks. Detoxification was usually initiated using reducing dosages of methadone or clonidine and lorazepam programmes. Patients were expected to attend discussion groups in their wards and occupational therapy in addition to individual psychiatric interviews. Attempts were made to help patients establish contact with local self help agencies, and outpatient support from both psychiatrists and psychiatric social workers was offered on discharge. As the service was a general psychiatric unit and not a specialised addiction unit the staff were not trained in specific dependence treatments.

Most patients did not maintain contact with the psychiatric service. Thirty seven $(55 \%)$ admissions were terminated by the patient before detoxification was complete, usually after only one or two days, and $25(76 \%)$ outpatient contacts (usually a monthly review appointment) ended prematurely in the view of the supervising psychiatrist. Drugs were provided on 80 occasions of extended contact, but maintenance treatment using methadone was started on only 10 occasions (mean duration 21.7 months, range one month to 10 years).

A review of the general practice records identified those patients who were using heroin at the time of their last medical contact. A patient was considered to be abstinent only if a minimum of six months after the last contact with the psychiatric service he had not used heroin (or other opiate drugs) for at least one month. Table II shows the results. Data were not available for 42 patients, who were spread quite evenly among the five groups of outcome (fig 1). Though we acknowledge the shortcomings of this evaluative design, our evidence did not suggest that patients who had started treatment of this type were any more likely to abstain from using heroin than those who did not (those not starting treatment, in fact, showed a better prognosis: $\left.\chi^{2}=4 \cdot 36,1 \mathrm{df}, \mathrm{p}<0.05\right)$

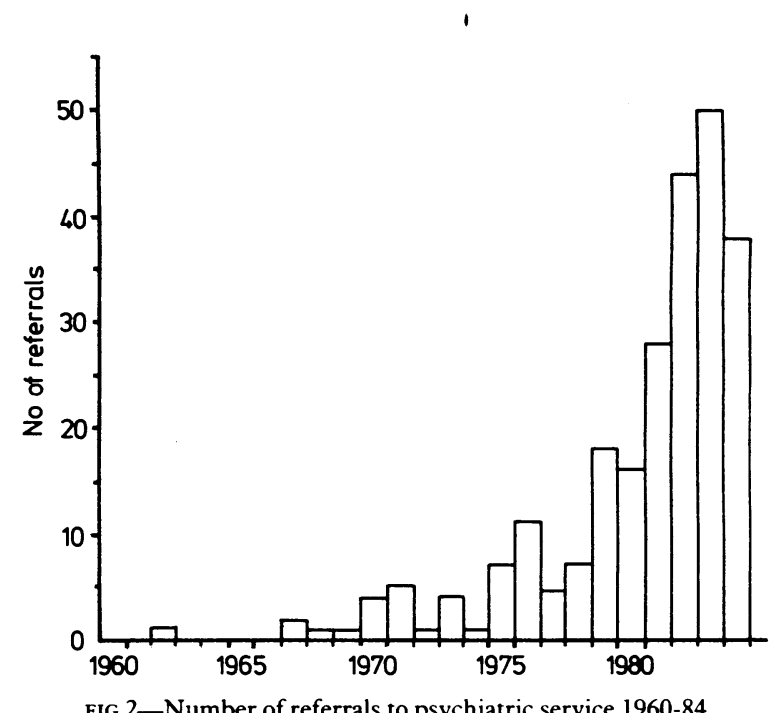

\section{Discussion}

The findings recorded in table II are of great interest. The evidence does not indicate that patients receiving treatment from the psychiatric drug treatment service have a higher rate of abstinence than those not starting treatment, casting doubt on the value of this type of service. The explanation for this result might be a bias towards the referral of only those patients thought to be most intractably affected by drug abuse. Reports from general practitioners, however, suggest that these patients invariably refuse contact with psychiatric services and are seldom referred. As in previous studies, it was the older drug abusers who were referred, younger abusers rarely coming to the attention of the psychiatric service. $^{79}$

Furthermore, it is evident from the high rates of non-attendance that few patients can effectively be said to have undertaken adequate treatment. This itself is evidence that patients find the service both uncomfortable and inappropriate. The drug abusers studied showed little psychopathology and rarely saw themselves as suf- fering from psychiatric illness. Their inclusion in a general psychiatric clinic was reported to be a major reason for nonattendance.

The lack of obvious success of the service may be reflected in the decline in the number of referrals since 1984, as practitioners and patients became progressively disillusioned with what was being offered. Major reasons for this lack of success could be the inadequacy of the selection procedures and conflicting expectations between the patient, referring practitioner, and psychiatrist. Currently, patients wishing to be referred attend an outpatient appointment at which the content of extended contact with the psychiatric service is explained. Attempts to assess motivation of the patients have proved time consuming and bear little relation to the patients' commitment to treatment and so have not played a major part in selection. Clearly a service such as this should be used selectively and realistic expectations obtained for all parties.

The relevance of psychiatric referral for every drug abuser is debatable, particularly if treatment is limited largely to withdrawal, as according to Newman: ". . . the challenge to clinicians lies entirely in maintaining abstinence once it has been achieved. This is not just the most difficult aspect of the problem; it is the only problem." ${ }^{10}$ Withdrawal may form only a minor part of treatment because heroin abuse, like alcohol abuse, is a remitting and relapsing disorder, with users spontaneously abstaining with little or no medical intervention. ${ }^{811}$ Claims for the efficacy of various treatments, based on abstinence at a fixed time after treatment, are unreliable and inappropriate, and to equate abstinence with cure is naive, if not dangerous. Studies evaluating or comparing treatments for drug dependence should therefore take into account the patterns of drug abuse by a patient before and after treatment, a simple "on/off" judgment being inadequate.

The remitting and relapsing pattern of heroin use is also important in devising treatment, which must accommodate the ups and downs in drug use over time; contacts must be continued despite repeated relapse. General practitioners may be in the best position to cope with the extended management of drug users, and certainly community based treatment seems more likely to maintain contacts. Accordingly, the treatment available must be varied and flexible, taking account of the differing needs of one patient over time or of several patients simultaneously. Psychiatric skill may be best used in encouraging community self help groups and group and family treatment. This function is unlikely to be met within existing resources.

Probably the greater part of the management of drug abuse will occur outside units specialising in dependence problems or even in units such as that described here. Debate and discussion are urgently required to clarify the appropriate style of management and network of services based in the community. There is a need for professionals such as psychologists, social workers, and specialist community workers with experience and skill in drug abuse, who are currently scarce, as general practitioners and non-specialist agency workers are at present left to face the task with little outside support. With emerging anxieties about the role of drug abusers in the dissemination of the acquired immune deficiency syndrome they are a group who cannot be ignored by society or the health service.

\section{References}

1 Scottish Home and Health Department Interdepartmental Committee on Drug Addiction. Second report: drug addiction. London: HMSO, 1965.

2 Social Services Committee. Fourth report, 1984-85: misuse of drugs. London: HMSO, 1985.

3 Jenner FA, Gill PV. Helping heroin addicts kick the habit. Br Med f 1985;291:344-5.

4 Kaplan J. The hardest drug: heroin and public policy. London: University of Chicago Press, 1983:153-7.

5 Advisory Council on the Misuse of Drugs. Treatment and rehabilitation. London: HMSO, 1982

6 Edwards G. British policies on opiate addiction. Br f Psychiatry 1979;134:1-13.

7 Love J, Gossop $M$. The process of referral and disposal within a London drug dependence clinic. $B r \mathcal{F}$ Addict 1985;80:435-40.

8 Robertson JR. Drug users in contact with general practice. Br Med 7 1985;290:34-5.

9 Fraser AA, Leighton KM. Characteristics of attenders at a Scottish drug dependence clinic. $\mathrm{Br} \mathcal{F}$ Psychiaty 1984;144:307-10.

10 Newman RG. The need to redefine "addiction." N Engl F Med 1983;308:1096-8.

11 Waldorf D. Life without heroin: some social adjustment during long term periods of voluntary abstention. In: Susman J, ed. Drug use and social policy. New York: AMS Press, 1972:471-86.

(Accepted 30 fanuary 1986) 